\title{
Medicalização no sistema de progressão continuada: inclusão ou omissão?^
}

\author{
Daniella Fernanda Moreira Santos, (D) $\star \star ~ S i l v a n a ~ C a l v o ~ T u l e s k i ~(\mathbb{D}$ \\ Universidade Estadual de Maringá, Paraná, PR, Brasil
}

\begin{abstract}
Resumo
Esse estudo teve como objetivo abordar o processo de medicalização da infância, realizando um mapeamento dos alunos do primeiro ciclo do ensino fundamental da rede municipal de uma cidade paranaense, que foram diagnosticados e medicados devido aos ditos transtornos de aprendizagem, entre eles o Transtorno de Déficit de Atenção e Hiperatividade (TDAH). Teve como intuito, também, discutir como o sistema de progressão continuada influencia o processo de escolarização destes alunos. Para tanto, foram combinadas as pesquisas empírica e bibliográfica, em que os dados da investigação de campo, obtidos por meio de questionários respondido pelos pais ou responsáveis, foram submetidos a análise quantitativa e qualitativa, e os resultados foram discutidos em conjunto com a revisão bibliográfica, a partir do referencial teórico da Psicologia Histórico-Cultural. Por meio desta pesquisa, foi possivel compreender que o fenômeno da medicalização cresce exponencialmente, sobretudo no cenário educacional, e que o sistema de progressão continuada, da forma como foi implantado, colabora para que essa problemática seja encoberta.
\end{abstract}

Palavras-chave: medicalização; psicologia histórico-cultural; progressão continuada.

\section{Medicalization in the continuous progression system: inclusion or omission?}

\begin{abstract}
This study aimed to address the childhood medicalization process, making a mapping of the students of the first cycle of elementary education in the municipal network of a city in Paraná, who were diagnosed and medicated due to the said learning disorders, among them, Attention Deficit Hyperactivity Disorder (ADHD). It was also intended to discuss how the system of continued progression influences the schooling process of these students. For this purpose, an empirical and bibliographic research was combined, in which the data of the field investigation, obtained through questionnaires answered by the parents or guardians, were submitted to quantitative and qualitative analysis and the results were discussed together with the bibliographic review, from the theoretical framework of Historical-Cultural Psychology. Through this research, it was clarified that the phenomenon of medicalization grows exponentially, especially in the educational scenario, and that the system of continued progression, as it was implemented, collaborates so that this problem is covered up.
\end{abstract}

Keywords: medicalization; historical-cultural psychology; continuous progress.

\section{Introdução}

A abordagem Histórico-Cultural, pautada no Materialismo Histórico-Dialético, tem como eixo norteador a ideia de que o indivíduo nasce dotado de funções elementares, comuns aos animais, mas somente humaniza-se, adquirindo as funções superiores propriamente humanas, a partir de sua atuação no meio material e social no qual está inserido, isto é, humaniza-se nas e pelas relações sociais, conforme discute Leontiev (2004). Destas relações sociais, responsáveis por promover o desenvolvimento humano, destaca-se o ensino escolar, que tem como função primordial garantir que o indivíduo aproprie-se das objetivações genéricas científicas, que são mais complexas e capazes de elevá-lo a um nível qualitativamente superior em termos de desenvolvimento psíquico (SAVIANI, 2011).

Essas premissas são amplamente difundidas no âmbito escolar e se constituem como base para os projetos políticos pedagógicos de incontáveis escolas brasileiras, de modo que se torna comum a expectativa de que neste segmento, desde o nível da atuação cotidiana até o nível das políticas educacionais, se conheça e utilize essa teoria para respaldar as práticas, compreendendo a importância

\footnotetext{
$\star$ Pesquisa financiada por PIBIC/CNPq-FA-UEM e aprovada pelo Comitê de Ética da Universidade Estadual de Maringá - CAE 06875112.0.0000.0104.

$\star \star$ Endereço para correspondência: Universidade Estadual de Maringá, Centro de Ciências Humanas Letras e Artes, Departamento de Psicologia. Av. Colombo, 5790 - zona 7 - Maringá, PR - Brasil. CEP: 87020900. E-mails: danii. fernanda@hotmail.com, silvanatuleski@gmail.com

Os dados completos das autoras encontram-se ao final do artigo.
}

do papel do professor, da mediação e aquisição de conhecimentos científicos. Entretanto, basta uma pesquisa mais aprofundada das atividades escolares cotidianas (SANTOS, TULESKI; FRANCO, 2016) para observar que as concepções que predominam nesse contexto são de ordem biologizante e individualizante, que apontam o aluno - e, no limite, sua família - como cerne de todas as dificuldades e responsável único pela superação das mesmas.

Silva (2011) explicita que a sociedade pós-moderna é caracterizada pela fluidez, fragmentação e individualização, e essas características "[...] acabam por gerar ansiedades e angústias que se manifestam sob diversas formas de sofrimento psíquico" (SILVA, 2011, p. 221). Geram sofrimento porque o indivíduo é apontado como o único responsável por seu sucesso e, consequentemente, por seu fracasso. Esse processo caracteriza-se como um recurso ideológico em que se apregoa uma sociedade perfeita, na qual apenas alguns indivíduos estão desajustados e precisam ser rapidamente regulados, ou serão excluídos.

Essas ideias encontraram solo fértil na educação, sendo amplamente difundidas, influenciando as práticas pedagógicas, o posicionamento dos professores e até mesmo a organização do ensino. Gentili (1996) emprega o termo mcdonaldização para discutir o processo de aligeiramento no sistema escolar, transformando-o em um mercado educacional altamente competitivo, aos moldes do mercado de trabalho. De modo que aqueles que não 
se encaixam nessa proposta são considerados disfuncionais, e a tentativa de adequá-los a esse mecanismo e recolocá-los na "corrida para o sucesso" vem por meio de "soluções" individuais, com frequência em forma de tratamento medicamentoso.

Partindo dessas considerações, este estudo teve como objetivo realizar um mapeamento do uso de medicação para os ditos transtornos de aprendizagem de uma cidade no interior do Paraná, discutindo quais são os aspectos que contribuem para a transformação de dificuldades no processo de ensino e aprendizagem em diagnósticos e uso de medicação por alunos. Entende-se que essa discussão se faz importante diante do fenômeno de medicalização observado atualmente nas escolas brasileiras (MOYSÉS; COLLARES, 2012) e da indiscutível necessidade de reverter este quadro, atuando em todos os níveis, isto é, desde as práticas singulares entre professor e aluno até o questionamento e revisão das políticas educacionais vigentes. Assim, este estudo faz um recorte desta ampla questão, dando enfoque a política de progressão continuada e sua influência no processo de medicalização. Utilizou-se, para fundamentar a discussão, o referencial teórico-metodológico da Psicologia Histórico-Cultural, compreendendo que tal corrente teórica apresenta argumentos suficientes para refutar a visão biologizante, apontando direções e práticas alternativas para a superação desta problemática.

\section{Sobre materiais e métodos}

Esta pesquisa envolveu investigações bibliográficas e de campo, sendo que o universo da pesquisa empírica restringiu-se ao primeiro ciclo do ensino fundamental das escolas municipais de um município de porte médio, localizado na região norte central do estado do Paraná. A escolha de tal fase do ciclo escolar se deu por ser nesse momento que o estudo passa a se caracterizar como a atividade principal do indivíduo. Segundo Vygotski (1996), nesta etapa, o estudo torna-se responsável por orientar o processo de desenvolvimento, reorganizando a personalidade da criança sobre uma nova base. Para tanto, esta atividade deve ser intencional, planejada e, no limite, ter por objetivo esse desenvolvimento.

Para a obtenção dos dados, aplicou-se um questionário aos responsáveis das crianças no momento da matrícula, ficando a critério deles respondê-los, de acordo com o Comitê de Ética em Pesquisa com Seres Humanos, número do CAE 06875112.0.0000.0104. O questionário visava investigar a existência de transtornos de aprendizagem nas crianças e o uso de medicação controlada para os mesmos. Os dados obtidos foram informatizados, sistematizados e, posteriormente, relacionados ao levantamento bibliográfico. Este foi realizado na base de dados Scielo, com os descritores: "metilfenidato" e "progressão continuada", de acordo com as discussões a serem realizadas. A busca se deu em "todos os índices" e, após triagem, foram obtidos 22 artigos que embasaram a discussão teórica deste estudo.

\section{Resultados}

Os dados coletados datam do final do ano de 2013. Neste ano, o total de alunos matriculados nas seis escolas de ensino fundamental do município foi de 1.863 , e foram obtidos 1.210 questionários válidos, o que corresponde a $65 \%$ da amostra. O resultado apontou que 70 alunos utilizam medicação para transtornos de aprendizagem e de controle do comportamento, o que corresponde a 5,8\% da amostra. Desses alunos, 51 são do sexo masculino, 18 do sexo feminino e um deles não informou. Já 1.140, ou seja, 94,2 \%, não utilizam medicação.

Com relação a essas crianças que fazem uso de medicação controlada, o medicamento mais utilizado, de acordo com os questionários, é a Ritalina, psicotrópico cuja substância ativa é o cloridrato de metilfenidato, utilizado por 55 das crianças pesquisadas. Destas, 49 fazem uso somente deste medicamento; um aluno faz uso da Ritalina associado ao Depakote; ${ }^{1}$ um aluno faz uso associado ao Daforin; ${ }^{2}$ um aluno utiliza, junto com a Ritalina, o medicamento Depakene; um aluno faz uso associado de Ritalina e Tofranil ${ }^{3}$ e dois alunos utilizam de forma combinada a Ritalina e a Resperidona, antipsicótico atípico utilizado para tratar determinados transtornos mentais, entre eles a esquizofrenia, o transtorno bipolar e irritabilidade associada ao transtorno do espectro autista (TEA). Este medicamento é apontado como o segundo medicamento mais utilizado, sendo indicado em 17 questionários. Além dos dois alunos que combinam a Ritalina e a Resperidona, um dos questionários também aponta o uso da Ritalina associado ao Clonazepam. ${ }^{4}$

Outro dado obtido foi em relação aos diagnósticos, isto é, para quais transtornos esses fármacos estão sendo prescritos e utilizados. De acordo com os questionários respondidos, o transtorno dominante no universo da pesquisa é o Transtorno de Déficit de Atenção e Hiperatividade (TDAH) sem outros transtornos associados, sendo esse o diagnóstico em 29 casos. Em seguida está o Déficit de Atenção, apontado em 13 questionários; em um caso, o diagnóstico é ansiedade; em 21 dos questionários, o diagnóstico não foi apontado; e outros seis questionários apontam o TDAH associado ao Déficit de Atenção, conforme a resposta dos pais e responsáveis.

Outro dado levantado foi a respeito do acompanhamento que as crianças diagnosticadas e medicadas recebem. E, sobre isso, observou-se que apenas 27 alunos possuíam outro tipo de atendimento, tais como: psicológico, psicopedagógico, fonoaudiológico e sala de recurso multifuncional. Esse dado demonstra que o medicamento tem sido a principal forma de "tratamento" das dificuldades de aprendizagem e controle do comportamento. No entanto, acrescenta-se que o remédio não tem como função promover o desenvolvimento das funções psicológicas superiores que apresentam déficit; portanto, uma vez que cesse o uso dos medicamentos, as crianças e as escolas não terão adquirido e/ou construído recursos para lidarem com as dificuldades existentes. 
A especialidade médica que mais prescreveu medicamentos de uso controlado para crianças do ensino fundamental foi a neurologia, indicada em 48 questionários. Outros profissionais também citados como responsáveis pelo diagnóstico e receita de medicação foram: psiquiatra, neuropediatra, pediatra e psicólogo. Apenas uma das crianças foi avaliada por dois profissionais (neurologista e psiquiatra).

Com relação às séries e o número de crianças medicadas, obteve-se que, no primeiro ano do ensino fundamental, o número de alunos medicados foi de três crianças; no segundo ano houve um grande salto nesse número, aumentando de três para 11 crianças. Já no terceiro ano o número dobra, passando de 11 alunos medicados para 22, mantendo-se essa média no quarto ano, com 21 alunos medicados; e no quinto ano esse número cai novamente, sendo sete crianças medicadas. Vale mencionar que, dos questionários que indicam crianças medicadas, seis não especificam em que ano escolar a criança se encontra. Com base nesses dados, evidencia-se que, no município pesquisado, há um pico de medicação no terceiro e quarto anos do ensino fundamental; além disso, o primeiro e o último anos deste ciclo educacional são os que menos contêm crianças que fazem uso de medicamento.

\section{Discussão}

Para a realização da discussão, os artigos foram agrupados em dois eixos temáticos e posteriormente relacionados aos dados empíricos obtidos por meio da aplicação dos questionários. O primeiro eixo temático trata do metilfenidato, medicamento apontado como o mais utilizado no tratamento de TDAH e suas incoerências, com o objetivo de discutir os motivos pelos quais o uso indiscriminado desse medicamento deve ser questionado. O segundo eixo temático trata das contradições da progressão continuada, com o intuito de discorrer sobre como essa forma de organização do ensino contribui com o fenômeno da medicalização. Esses eixos, juntos, visam explicitar o cenário que se apresenta ao aluno medicado por supostas dificuldades de aprendizagem e de controle de comportamento, principais causas da busca por diagnóstico, segundo os questionários.

\section{O metilfenidato e suas controvérsias}

Esse item visa discutir o uso abusivo do metilfenidato, indicando que, apesar de ser a mais utilizada, esta nem sempre é a forma ideal de tratamento, tampouco deveria ser a única. Para tanto, foram utilizados nove artigos devidamente selecionados a partir do descritor "metilfenidato", sendo que todos apresentam e discutem o metilfenidato como fármaco utilizado principalmente no tratamento do Transtorno de Déficit de Atenção e Hiperatividade (TDAH), e, desses, sete alertam para o uso indiscriminado do medicamento e suas consequências.

No Brasil, o metilfenidato é comercializado sob as marcas comerciais Ritalina e Concerta, sendo considerado o tratamento de primeira escolha e o mais utilizado em casos de TDAH desde o início de sua comercialização (BRZOZOWSKI; DIEHL, 2013; CESAR et al., 2012). Seus efeitos considerados terapêuticos incluem redução da hiperatividade, da impulsividade e da desatenção e aumento de comportamentos como a manutenção do foco em uma tarefa, o desempenho acadêmico e escolar e as relações sociais (FARAONE; BUITELAR, 2010 apud BRZOZOWSKI; DIEHL, 2013).

Camargos Jr. e Nicolato (2009) expõem que, por se tratar de um psicotrópico, a prescrição do metilfenidato é restritiva no Brasil, contudo sua venda tem crescido constantemente. Cesar et al. (2012) alertam que a produção desse medicamento aumentou $298 \%$ no período de 1996 a 2006. Caliman e Dimitrovic (2013) também indicam o aumento no uso do medicamento, destacando que o sexo masculino é o maior alvo dessas prescrições, que os pediatras e generalistas são os maiores prescritores do psicoestimulante e que há maior frequência na população de sete a 15 anos, com progressivo aumento das medicações de ação prolongada.

Brzozowski e Diehl (2013) discutem que o diagnóstico, principalmente no caso de TDAH, torna-se muito significativo, pois apresenta uma exculpação para a família e para a própria criança. Isso ocorre porque o diagnóstico justifica os comportamentos considerados inadequados, como algo que está para além da vontade da criança ou do meio em que ela se encontra. Além disso, Brant e Carvalho (2012) apontam para o uso sem fins medicinais do metilfenidato, afirmando que este vem sendo utilizado como um medicamento gadget, empregado na busca de reconhecimento social, no uso recreativo e voltado para a produção.

Para além da crescente utilização desse fármaco, os artigos discutem também seus possíveis efeitos colaterais. De acordo com Caliman e Rodrigues (2014), as discussões sobre o metilfenidato são marcadas pela polarização de pontos de vista, ora indicado como o medicamento mais eficaz no tratamento do TDAH, ora descrito criticamente como a "droga da obediência". Cesar et al. (2012) e Vendruscolo e Takahashi (2011) expõem que estudos têm sugerido que indivíduos que tomam ou tomaram por muito tempo estimulantes prescritos são mais propensos a usar outras drogas do que aqueles que nunca fizeram uso desses medicamentos. Brant e Carvalho (2012) também indicam que o metilfenidato pode revelar-se altamente propenso à dependência. Durval Damiani, Daniel Damiani e Casella (2010) discutem a influência do uso de metilfenidato no baixo crescimento estatural em crianças, indicando que, se isso ocorre, não parece ser tão significativo e que a opção pela medicação não deveria deixar de ocorrer por esse motivo.

De modo geral, o que se verifica ao investigar a literatura a respeito do metilfenidato é que a grande maioria dos autores aponta que o uso desse fármaco deve ser feito de maneira cautelosa, pois pode apresentar riscos aos indivíduos (BRANT; CARVALHO, 2012; VENDRUSCOLO; TAKAHASHI, 2011; CESAR et al., 2012). No entanto, há também uma parcela de pesquisadores que afirma que os benefícios do uso da medicação são maiores que os possíveis efeitos colaterais (DAMIANI, Durval; DAMIANI, Daniel; CASELLA, 2010).

Fractal, Rev. Psicol., v. 32 - n. 2, p. 154-161, 2020 
Conforme os dados obtidos por meio da pesquisa de campo, a grande maioria das crianças é medicada com Ritalina, sendo o TDAH o principal transtorno para o qual esse medicamento é indicado. É observado ainda que, em consonância com os dados de Caliman e Dimitrovic (2013), a maioria das crianças medicadas é do sexo masculino, no entanto, a especialidade médica que mais prescreve a medicação, no contexto pesquisado, é o neurologista, e não generalistas e pediatras, conforme indicam essas autoras.

A despeito de seus efeitos colaterais, a pesquisa de campo aponta que a maioria dos alunos medicados tem o fármaco como única forma de tratamento e não recebe acompanhamento de outra especialidade. Sobre esse aspecto, Moysés e Collares (2012) alertam que esse psicoestimulante pode ser capaz de aumentar a concentração e a atenção, potencialmente focando melhor o raciocínio e aumentando a cognição; contudo o "preço" a ser pago, isto é, os efeitos colaterais, físicos e sociais, são muito significativos, dentre os quais se podem citar, entre os mais comuns: nervosismo, insônia, diminuição de apetite, dor abdominal, náusea, vômito. Ademais, Moysés e Collares (2012) citam e discutem o fato de que esse fármaco possui uma ampla gama de possíveis efeitos colaterais mais graves, que vão desde a dessensibilização do cérebro em relação os pequenos prazeres cotidianos, como alimentos, emoções e interações sociais, até a maior propensão ao envolvimento com drogas ilícitas.

Portanto, o que se destaca é que este fármaco é um psicoestimulante com ações severas no organismo, por isso não deve ser banalizado. Acrescenta-se o fato de que os "consumidores" são crianças, em processo de desenvolvimento, que não deveriam estar sujeitas a uma droga dessa natureza sem que isso fosse extremamente necessário. Mas o que se observa é que esse medicamento tem sido a primeira opção diante de comportamentos inadequados ou de mínimas dificuldades de aprendizagem no contexto escolar. E, nesse sentido, a função que deveria ser da prática pedagógica, isto é, atuar com a criança para que ela venha a superar as dificuldades apresentadas, é relegada ao medicamento, e o ensino acaba por não cumprir a sua função primordial de promover desenvolvimento psíquico. Assim, a escola, esfera social que deveria ser fonte de práticas que antecipam e promovem o desenvolvimento humano, como propunha Vygotski (2006), elevando o indivíduo a níveis qualitativamente superiores, perde sua força, torna-se esvaziada de sentido.

Esse cenário evidencia um fenômeno extremamente prejudicial ao desenvolvimento das crianças, que, diante de dificuldades de aprendizagem e/ou de controle do comportamento, principais causas da busca por diagnóstico, conforme os questionários, são prontamente diagnosticadas, medicadas e rotuladas, sem chances de desenvolverem, de fato, funções, capacidades e habilidades que poderiam levar à superação deste quadro. No entanto, a despeito da gravidade desse fenômeno, ele tem sido mascarado por diversos aspectos: concepções ideológicas que defendem a medicação como única solução possível, ignorando a ampla gama de efeitos colaterais existentes; formação deficitária de professores e demais profissionais da educação, que não compreendem a função primordial da mesma para o desenvolvimento humano; falta de recursos concretos para atuar no cotidiano escolar, promovendo práticas pedagógicas de qualidade. Incluem-se, ainda, questões mais amplas, como a própria organização do ensino.

\section{As contradições da progressão continuada}

Ao tratar do uso abusivo de medicamentos nas escolas brasileiras, é necessário compreender o contexto em que esse fenômeno ocorre, e, no caso do ensino fundamental, um aspecto que não pode ser ignorado é o sistema de progressão continuada, por meio do qual os alunos são avaliados qualitativamente e, no limite, não há reprovação. Esta sessão tem como objetivo discutir a relação da aprovação automática dos alunos com diagnóstico e que fazem uso de medicamentos para transtornos de aprendizagem e de controle do comportamento.

O levantamento bibliográfico apontou treze artigos que permeiam essa discussão, encontrados por meio do descritor "progressão continuada". A educação escolar é um direito fundamental do homem, por ser compreendida como condição sine qua non para o desenvolvimento humano. Contudo, considerando a realidade da educação pública brasileira, observa-se que o processo educacional não tem sido eficaz em atender às necessidades de todos os grupos sociais, conforme indica Jacomini (2009). Reiterando essa ideia, Viégas (2015) e Cianflone e Andrade (2007) indicam que o fracasso escolar é um problema antigo que se cronificou, promovendo considerável número de reprovações e evasões escolares, que se caracterizam como uma das grandes adversidades da educação pública brasileira.

Jacomini (2009) defende que, nesse cenário, tornou-se fundamental questionar a promoção como legitimadora da aprendizagem e buscar um processo educativo que rompa com a dicotomia promoção-reprovação, eliminando as medidas classificatórias. Para a autora, quando o ensino se estabelece como promotor de desenvolvimento, não há qualquer justificativa pedagógica para a reprovação. Nesse mesmo sentido, Paro (2011) esclarece que a reprovação tem um caráter antipedagógico, servindo apenas para lançar sobre o aluno a culpa pela incompetência, que, no limite, é do próprio sistema de ensino. Com base em concepções dessa natureza, foram elaboradas propostas de organização do ensino em ciclos e de progressão continuada, conforme indica Jacomini (2009).

Segundo Miranda (2009) e Jacomini (2014), as discussões a respeito da progressão continuada datam da década de 1920; contudo, foi principalmente nos anos de 1990, em especial após a promulgação da Lei de Diretrizes e Bases da Educação Nacional (Lei no. 9.394/96), que muitas redes de ensino, principalmente nas regiões Sul e Sudeste do país, implementaram a reorganização do sistema de ensino. De acordo com Bertagna (2010), com esse sistema se espera que a escola encontre diferentes formas de ensinar, assegurando a aprendizagem dos alunos e o seu progresso intra e interciclos. Todavia, Jacomini (2009) expõe que a implantação dessa organização 
divide opiniões. Para alguns, a não reprovação apenas mascararia as dificuldades de aprendizagem, como defende Demo (1998, p. 159 apud JACOMINI, 2009, p. 567) ao dizer que "[...] a promoção, tornando-se automática, escamoteia a falta de aprendizagem, levando a escola pública de modo ainda mais rápido e fatal a ser reconhecida como coisa pobre para o pobre". Por este motivo, autores como Paro (2011) e Luciene Naiff e Denis Naiff (2013) alertam que novas práticas requerem novas concepções que as embasem, sem as quais qualquer mudança fica limitada a ações esvaziadas de sentido.

Além da dúvida sobre a eficácia desse sistema por parte de teóricos da educação, também há resistência em relação à progressão continuada por parte dos professores, pais e sociedade em geral, como registram Cianflone e Andrade (2007). Tal resistência advém da ideia tradicional de que a reprovação (ou o medo dela) "obriga" o aluno a estudar e, consequentemente, melhorar seu desempenho em sala de aula. Jacomini (2011) também indica que os pais são contra o sistema de progressão continuada, pois têm dificuldades em interpretar os dados qualitativos do desempenho dos filhos, visto que nesse sistema a avaliação é difusa e sem medidas exatas, ficando mais difícil para eles controlarem o desempenho da criança na escola. Luciene Naiff e Denis Naiff (2013) apontam para representações negativas dos professores sobre organização em ciclos, devido às dificuldades em abandonar práticas avaliativas típicas do regime seriado, o que necessariamente implicaria mudanças no trabalho docente.

Dias, Enumo e Turini (2006) expõem que, na prática, a "flexibilização" do sistema de avaliação não se relaciona a uma melhor qualidade do ensino, e evidenciam a necessidade de rever a implantação da progressão continuada, de modo que as ideias fundamentadas e bem-intencionadas consigam efetivar-se na prática, tal como se propõem teoricamente. Cianflone e Andrade (2007) acrescentam que a progressão continuada requer mudanças também nas atividades cotidianas de sala de aula e nas avaliações, pois se o aprendizado é encarado como um processo, a avaliação também deve se configurar desta forma.

Marcondes e Sigolo (2012) explicitam que, no que tange à progressão continuada, docentes, responsáveis e alunos são meros expectadores desta política educacional. Segundo os autores, as informações superficiais trocadas entre família e escola provocaram desencontros e interpretações equivocadas a respeito do funcionamento dos ciclos no ensino fundamental. Para Bahia (2009), muito pouco foi proposto em relação à formação docente, na direção da compreensão dos pressupostos da progressão continuada, faltando a instrumentalização necessária para lidar com esse sistema pedagógico. Do exposto, torna-se evidente, conforme Viégas (2015) explicita, que a progressão continuada ainda não superou o fracasso escolar, mas tornou o problema "invisível" nesse contexto, e as vítimas continuam a ser culpabilizadas.

Por outro lado, há argumentos que defendem a progressão continuada como um sistema mais adequado para tornar a educação mais igualitária e menos excludente. Paro (2011), por exemplo, afirma que é preciso compreender que o que produz o não aprendizado é o ensino incompetente, e é este que precisa ser mudado, pois a promoção do aluno é inerente ao bom ensino, de modo que a falha não está no sistema de progressão continuada, especificamente, mas em uma ampla série de aspectos que permeiam a educação. Em concordância, Bahia (2009) reconhece que os equívocos em relação a tal proposta acabaram por gerar descrença sobre sua eficácia, tais como a distância entre as intenções oficiais e o que efetivamente ocorreu no cotidiano escolar. Já Miranda (2009) afirma que, neste sistema, uma vez que os desafios sejam enfrentados e superados, o direito à escola estaria mais bem assegurado, o acesso e a permanência estariam garantidos a todos, construindo uma escola mais democrática, justa e equitativa.

Dessa breve síntese, percebe-se que a progressão continuada tem se mostrado bastante contraditória. Por um lado, defende-se que, se bem instrumentalizada, embasada e aplicada, sustentaria a superação da exclusão e evasão escolar. Por outro lado, uma vez que não se realiza uma reforma por completo na educação - incluindo formação de qualidade para os professores, condições estruturais e físicas, planejamento pedagógico, apoio político e econômico -, a aprovação automática serve apenas para formar mais indivíduos que, apesar de frequentarem a escola, não se beneficiam do desenvolvimento que deveria ser proporcionado pela educação.

Vale ressaltar que este não é um problema somente educacional, são questões existentes na sociedade e reproduzidas no contexto escolar, conforme indica Lemos (2013). A escola é um contexto multideterminado, e os problemas contidos nela também o são; tratar esse contexto como reflexo de problemas individuais é terreno fértil, de acordo com Viégas (2015), para a medicalização no contexto escolar, pois, diante da dificuldade de aprendizagem, ao invés de se ter como foco as práticas pedagógicas e relações interpessoais, responsabiliza-se o sujeito singular.

Cabe problematizar ainda como o sistema de progressão continuada influencia o processo de escolarização dos alunos diagnosticados e medicados por transtornos de aprendizagem nas escolas-alvo da pesquisa. Voltamos às proposições de Vygotski (2006), que defende que o ensino deve se antecipar ao desenvolvimento para então promovê-lo; no limite, essa formulação segue a premissa da formação social da mente, isto é, para que o homem se desenvolva, é necessário que haja um par superior provocando nele a necessidade desse desenvolvimento e oferecendo instrumentos para que isso ocorra. Portanto, se em condições normais de ensino e aprendizagem é necessário que existam práticas de qualidade e que visem ao desenvolvimento, quando se depara com as dificuldades de aprendizagem, as práticas pedagógicas ganham ainda mais importância, se tornam fundamentais. Considerando que a progressão continuada não apresenta taxas de reprovação, abre espaço para que as práticas pedagógicas sejam afrouxadas, e os alunos com dificuldades de aprendizagem e "silenciados" pelo uso da medicação acabam à margem do fluxo de aprendizagem, sem nem ao menos se "incomodarem" por isso. 
A progressão continuada tem como objetivo não classificar o aluno, expondo e prejudicando aqueles que apresentam alguma dificuldade na aprendizagem. No entanto, esse objetivo só se cumpre se algo for feito a respeito daqueles que, por algum motivo, não acompanham os demais, se houver um trabalho que busque auxiliar o aluno em sua dificuldade, visando a colocá-lo na média. Para tanto, é necessário manter constantemente um olhar crítico sobre as práticas de ensino, as políticas públicas, a atuação dos profissionais envolvidos, a relação que a esfera escolar estabelece com a família e com o próprio aluno. Somente ações intersetoriais, intencionais e de qualidade são capazes de promover o desenvolvimento do aluno e a superação das visões biologizantes que, por sua vez, não buscam evolução, mas somente justificativas. Do contrário, a não reprovação acaba por mascarar as dificuldades que, ao não serem trabalhadas, irão acumular-se e eclodir no segundo ciclo do ensino fundamental, apenas atrasando e dificultando a possibilidade de superação. $\mathrm{O}$ diagnóstico e o uso de medicação surgem nesse cenário como paliativos para conter comportamentos inadequados, mas não necessariamente para promover uma aprendizagem de qualidade.

\section{Breves considerações}

As dificuldades na relação ensino-aprendizagem são encaradas como transtornos por diversos motivos, que perpassam concepções individualizantes arraigadas, políticas educacionais falhas, estrutura escolar empobrecida, falta de investimento e incentivo à educação, até o fato de a "resolução" de um transtorno ser objetiva, vinda de fármacos, e não exigir nenhuma ação diferenciada ou mudança de conduta da escola, família e sociedade. Trata-se de um processo que contém múltiplas contradições, que, somadas, culminam nos fenômenos de biologização e medicalização do processo educacional.

O cenário evidenciado pela pesquisa é de um significativo número de crianças diagnosticadas e medicadas, número este que, segundo o levantamento bibliográfico, tem aumentado exponencialmente. Ao mesmo tempo, esse movimento tem sido mascarado pela progressão continuada, sistema que, em sua teoria, tem como justificativa a não exclusão ou rotulação dos indivíduos, mas que, na prática, se mostra inconsistente e, no limite, além de não atingir seu objetivo primordial, acaba por aprofundar os problemas de aprendizagem. Assim, as dificuldades dos alunos não são trabalhadas em sala de aula e acabam por ser "trabalhadas" nos consultórios médicos e na "fila da Ritalina", prática comum nas escolas, que não assumem para si a função de superar as dificuldades pedagógicas, por meio de práticas pedagógicas, mas buscam superá-las ou acobertá-las por meio e com a ajuda das práticas clínicas.

Considerando os limites da pesquisa, mas diante dos dados obtidos, torna-se importante questionar quais procedimentos deveriam ser adotados por educadores e psicólogos escolares a fim de combater a medicalização. Que práticas pedagógicas dariam conta de proporcionar a aprendizagem efetiva sem recorrer à medicação? A investigação detalhada da gênese e desenvolvimento das dificuldades, tal como proposta por Vigotski (1997) em seus estudos pedológicos, requer um olhar cuidadoso para as múltiplas relações (sociais gerais, familiares, escolares, etc.) que cercam esse processo, para então articular ações terapêuticas necessárias à sua superação, o que, em nossa concepção, é o caminho mais adequado. Ou seja, um problema complexo tem também uma origem complexa, que não deve ser buscada em um único elemento, mas compreendida no contexto em que surge e, sobretudo, no processo que leva à sua formação. Olhar para a criança apenas como portadora de um transtorno é trabalhar unicamente com o resultado de uma questão que é, no limite, processual. Este trabalho é longo e muitas vezes demorado, mas seu resultado é imensamente mais benéfico para o desenvolvimento da criança.

Então, por que o ciclo de reprodução de práticas aligeiradas se perpetua, apesar das inúmeras críticas realizadas desde o final do século XX a tais procedimentos? Arrisca-se aqui afirmar que tais perguntas são apenas a ponta do iceberg da sociedade capitalista atual, que todas as esferas da sociabilidade vêm reproduzindo mecanismos cada vez mais desumanizadores. Deslocar a análise dos fenômenos das relações sociais para o indivíduo é um mecanismo ideológico que se perpetua desde a origem da sociedade burguesa, velando sua essência contraditória e desigual.

$\mathrm{O}$ fato de se conceber as dificuldades escolares como transtornos impede que se vislumbre a precarização na formação dos docentes, que se questionem as políticas educacionais equivocadas e assistencialistas, que se denuncie a desvalorização da função do educador resultante de arrocho salarial e exposição às condições precárias de ensino, que se discutam as propostas pedagógicas ineficazes pela discrepância entre teoria e prática. As diversas relações pauperizadas que resultam nos problemas de escolarização acabam por ser traduzidas como transtornos, e estes apontados como responsáveis pelas dificuldades na aquisição de habilidades culturais como leitura, escrita e operações matemáticas. Assim, é pertinente levantar a questão: seria o transtorno a afetar essas aquisições, ou justamente pelo fato de essas aquisições estarem sendo precarizadas, devido às condições externas e internas à escola, as crianças têm se apresentado mais dispersas e desatentas, contribuindo para um diagnóstico aligeirado de transtorno? É fundamental avançarmos na direção de nos aprofundarmos a respeito das relações que subjazem e sustentam as práticas medicamentosas para "corrigir" problemas nos processos educativos, pois, sem promover questionamentos dessa natureza, recorre-se à medicação daqueles que não se adaptam a esse sistema perverso, ao invés de se implementarem práticas pedagógicas humanizadoras. 


\section{Informações sobre as autoras:}

Daniella Fernanda Moreira Santos

(iD) https://orcid.org/0000-0001-6086-6437

(9) http://lattes.cnpq.br/7552881634820298

Psicóloga e mestre em Psicologia pela Universidade Estadual de Maringá, PR, Brasil.

\section{Silvana Calvo Tuleski}

iD https://orcid.org/0000-0002-6967-2548

(9) http://lattes.cnpq.br/0105108434995580

Doutora e pós-doutora em Educação Escolar pela UNESP Araraquara. Professora associada da graduação e pós-graduação em Psicologia do Departamento de Psicologia da Universidade Estadual de Maringá, PR, Brasil.

\section{Contribuição das autoras:}

As autoras colaboraram ao longo do processo, desde a elaboração até a revisão final do manuscrito. Ambas aprovaram o manuscrito final para publicação.

\section{Como citar este artigo:}

\section{ABNT}

SANTOS, Daniella Fernanda Moreira; TULESKI, Silvana Calvo. Medicalização no sistema de progressão continuada: inclusão ou omissão?. Fractal: Revista de Psicologia, Niterói, v. 32, n. 2, p. 154-161, maio./ago. 2020. https://doi.org/10.22409/1984-0292/ v32i2/5704

\section{APA}

Santos, D. F. M., \& Tuleski, S. C.. (2020, Maio/Agosto). Medicalização no sistema de progressão continuada: inclusão ou omissão?. Fractal: Revista de Psicologia, 32(2), 154-161. doi: https://doi.org/10.22409/1984-0292/v32i2/5704

\section{Copyright:}

Copyright (C) 2020 Santos, D. F. M., \& Tuleski, S. C. Este é um artigo em acesso aberto distribuído nos termos da Licença Creative Commons Atribuição que permite o uso irrestrito, a distribuição e reprodução em qualquer meio desde que o artigo original seja devidamente citado.

Copyright (C) 2020 Santos, D. F. M., \& Tuleski, S. C. This is an Open Access article distributed under the terms of the Creative Commons Attribution License, which permits unrestricted use, distribution, and reproduction in any medium, provided the original article is properly cited.

\section{Referências}

BAHIA, Norinês Panicacci. Formação de professores em serviço: fragilidades e descompassos no enfrentamento do fracasso escolar. Educação e Pesquisa, São Paulo, v. 35, n. 2, p. 317-329, 2009. https://doi.org/10.1590/S151797022009000200007

BERTAGNA, Regiane Helena. Avaliação e progressão continuada: o que a realidade desvela. Pro-Posições, Campinas, v. 21, n. 3, p. 193-218, 2010. https://doi.org/10.1590/S010373072010000300012

BRANT, Luiz Carlos; CARVALHO, Tales Renato Ferreira. Metilfenidato: medicamento gadget da contemporaneidade. Interface, Botucatu, v. 16, n. 42, p. 623-636, 2012. https://doi. org/10.1590/S1414-32832012000300004
BRZOZOWSKI, Fabiola Stolf; DIEHL, Eliana Elizabeth. Transtorno de déficit de atenção/hiperatividade: o diagnóstico pode ser terapêutico? Psicologia em Estudo, Maringá, v. 18, n. 4, p. 657-665, 2013. Disponível em: https://doi.org/10.1590/ S1413-73722013000400008

CALIMAN, Luciana Vieira; DOMITROVIC, Natália. Uma análise da dispensa pública do metilfenidato no Brasil: o caso do Espírito Santo. Physis, Rio de Janeiro, v. 23, n. 3, p. 879-902, 2013. https://doi.org/10.1590/S0103-73312013000300012

CALIMAN, Luciana Vieira; RODRIGUES, Pedro Henrique Pirovani. A experiência do uso de metilfenidato em adultos diagnosticados com TDAH. Psicologia em Estudo, Maringá, v. 19, n. 1, p. 125-134, 2014. https://doi.org/10.1590/14137372189590012

CAMARGOS JR., Walter; NICOLATO, Rodrigo. Características das prescrições no transtorno de déficit de atenção/hiperatividade. Jornal Brasileiro de Psiquiatria, Rio de Janeiro, v. 58, n. 3, p. 195-199, 2009. https://doi.org/10.1590/ S0047-20852009000300009

CESAR, Eduardo Luiz da Rocha et al. Uso prescrito de cloridrato de metilfenidato e correlatos entre estudantes universitários brasileiros. Revista Psiquiatria Clínica, São Paulo, v. 39, n. 6, p. 183-188, 2012. https://doi.org/10.1590/ S0101-60832012000600001

CIANFLONE, Ana Raquel Lucato; ANDRADE, Érika Natacha Fernandes de. Práticas avaliativas no ensino fundamental e cultura escolar. Paidéia, Ribeirão Preto, v. 17, n. 38, p. 389-402, 2007. https://doi.org/10.1590/S0103-863X2007000300009

DAMIANI, Durval; DAMIANI, Daniel; CASELLA, Erasmo. Hiperatividade e déficit de atenção: o tratamento prejudica o crescimento estatural? Arquivos Brasileiros de Endocrinologia e Metabologia, São Paulo, v. 54, n. 3, p. 262-268, 2010. https:// doi.org/10.1590/S0004-27302010000300003

DIAS, Tatiane Lebre; ENUMO, Sônia Regina Fiorim; TURINI, Flávia Almeida. Avaliação do desempenho acadêmico de alunos do ensino fundamental em Vitória, Espírito Santo. Estudos de Psicologia, Campinas, v. 23, n. 4, p. 381-390, 2006. https://doi. org/10.1590/S0103-166X2006000400006

GENTILI, Pablo. Neoliberalismo e educação: manual do usuário. In: SILVA, Tomaz Tadeu da; GENTILI, Pablo. (Org.) Escola $S$. A.: quem ganha e quem perde no mercado educacional do neoliberalismo. Brasília: CNTE, 1996. p. 9-49.

JACOMINI, Márcia Aparecida. Educar sem reprovar: desafio de uma escola para todos. Educação e Pesquisa, São Paulo, v. 35 , n. 3 , p. $557-572,2009$. https://doi.org/10.1590/S151797022009000300010

JACOMINI, Márcia Aparecida. Os ciclos e a progressão continuada na opinião de pais e alunos. Educação em Revista, Belo Horizonte, v. 27, n. 1, p. 161-180, 2011. https://doi. org/10.1590/S0102-46982011000100008

JACOMINI, Márcia Aparecida. Avaliação da aprendizagem em tempos de progressão continuada: o que mudou? Um estudo de teses e dissertações sobre o tema (2000-2010). Ensaio: Avaliação e Políticas Públicas em Educação [online], Rio de Janeiro, v. 22, n. 84, p. 807-828, 2014. https://doi.org/10.1590/ S0104-40362014000300010 
LEMOS, Valter. Políticas públicas de educação: equidade e sucesso escolar. Sociologia, Problemas e Práticas, Oeiras, n. 73, p. 151-169, 2013. http://dx.doi.org/10.7458/ SPP2013732812

LEONTIEV, Alexei Nikolaevich. $O$ desenvolvimento do psiquismo. Tradução de Rubens Eduardo Frias. 2 ed. São Paulo: Centauro, 2004.

MARCONDES, Keila Hellen Barbato; SIGOLO, Silvia Regina Ricco Lucato. Comunicação e envolvimento: possibilidades de interconexões entre família-escola?. Paidéia, Ribeirão Preto, v. 22, n. 51, p. 91-99, 2012. https://doi.org/10.1590/S0103863X2012000100011

MIRANDA, Marília Gouveia de. A organização escolar em ciclos e a questão da igualdade substantiva. Revista Brasileira de Educação, Rio de Janeiro, v. 14, n. 40, p. 24-34, Abr. 2009. https://doi.org/10.1590/S1413-24782009000100003

MOYSÉS, Maria Aparecida Afonso; COLLARES, Cecília Azevedo Lima. O lado escuro da dislexia e do TDAH. In: FACCI, Marilda Gonçalves Dias; MEIRA, Marisa Eugênia Melillo; TULESKI, Silvana Calvo (Org.). A exclusão dos "incluídos": uma crítica da Psicologia da Educação à patologização e medicalização dos processos educativos. 2. ed. Maringá: UEM, 2012. p. 107-155.

NAIFF, Luciene Alves Miguez; NAIFF, Denis Giovani Monteiro. Organização da escolaridade em ciclos: representações sociais de professores. Psicologia e Sociedade, Belo Horizonte, v. 25, n. 3, p. 538-548, 2013. https://doi. org/10.1590/S0102-71822013000300008

PARO, Vitor Henrique. Progressão continuada, supervisão escolar e avaliação externa: implicações para a qualidade do ensino. Revista Brasileira de Educação, Rio de Janeiro, v. 16, n. 48, p. 695-716, 2011. https://doi.org/10.1590/S141324782011000300009

SANTOS, Daniella Fernanda Moreira; TULESKI, Silvana Calvo; FRANCO, Adriana de Fátima. TDAH e boa avaliação no IDEB: uma correlação possível? Psicologia Escolar $e$ Educacional, Maringá, v. 20, n. 3, p. 515-522, 2016. https://doi. org/10.1590/2175-3539201502031037

SAVIANI, Demerval. Pedagogia histórico-crítica: primeiras aproximações. 11. ed. Campinas: Autores Associados, 2011.

SILVA, Renata da. A biologização das emoções e a medicalização da vida: contribuições da psicologia históricocultural para a compreensão da sociedade contemporânea. 2011. 279f. Dissertação (Mestrado) - Programa de Pós-graduação em Psicologia da Universidade Estadual de Maringá, Maringá, 2011. Disponível em: http://www.ppi.uem.br/arquivos-paralinks/teses-e-dissertacoes/2011/renata. Acesso em: 12 out. 2019.

VENDRUSCOLO, Leandro Franco; TAKAHASHI, Reinaldo Naoto. Comorbidade entre o transtorno de déficit de atenção/ hiperatividade e o abuso e dependência de álcool e outras drogas: evidências por meio de modelos animais. Revista Brasileira de Psiquiatria, São Paulo, v. 33, n. 2, p. 203-208, 2011. https://doi.org/10.1590/S1516-44462010005000011

VIEGAS, Lygia de Sousa. Progressão continuada e patologização da educação: um debate necessário. Psicologia Escolar e Educacional, Maringá, v. 19, n. 1, p. 153-161, 2015. https://doi.org/10.1590/2175-3539/2015/0191815

VYGOTSKI, Lev Semionovich. Obras Escogidas. Madrid: Visor, 1996. t. 4.

Fractal, Rev. Psicol., v. 32 - n. 2, p. 154-161, 2020
VIGOTSKI, Lev Semionovich. Diagnóstico do desenvolvimento e clínica pedológica da infância difícil [Esquema de investigação pedológica]. Madrid: Visor y Ministério de Educación y Ciencia, 1997. Obras Escogidas, t. 5, p. 275-338.

VIGOTSKI, Lev Semionovich. Aprendizagem e desenvolvimento intelectual na idade escolar. In: VIGOTSKI, Lev Semionovich; LURIA, Alexander Romanovich; LEONTIEV, Alexei Nikolaevich. Linguagem, desenvolvimento e aprendizagem. 10. ed. São Paulo: Ícone, 2006. p. 103-117. 